\title{
Broadening Understandings of the Cultural Value of Aloha in a Teacher Educator Program
}

\author{
Michele Ebersole* \\ University of Hawai'i at Hilo \\ Huihui Kanahele-Mossman \\ Edith Kanaka'ole Foundation \\ *Corresponding Author: mebersol@hawaii.edu \\ Received : 2020-07-15 \\ Accepted : 2020-11-30
}

DOI: $10.46303 /$ jcve.2020.14

\section{Abstract}

This study examined how pre-service teachers' in a mainstream teacher education program expanded their understandings of the Hawaiian cultural value of aloha to reflect the integrity of the translation of aloha as originating in Hawaiian ancestral text. Data were collected from 10 elementary and 12 secondary pre-service teachers' personal written reflections at the end of each day of a three-day course titled, "Teaching in Hawai'i's Schools." A post-course questionnaire was collected 10 months post-course completion, after pre-service teachers' student teaching experience. As a result of qualitatively analyzing their written reflections and post-course questionnaire three patterns emerged to reflect the shifts in their understanding of the word aloha: (1) Common Understandings of Aloha; (2) Methods for Activating Aloha; and (3) Sustainable Practices. Sixteen out of 22 or $73 \%$ of the pre-service teachers confirmed that they experienced a shift in their understanding of aloha. Of the remaining six who responded their understandings of aloha did not "shift," five of them used the following words to indicate that their understanding of aloha: "expanded," "strengthened," "influenced," "renewed," and "broadened" suggesting that their understanding of the word changed. In order for pre-service teachers to be comfortable with the language and meanings associated with a cultural value laden concept like aloha they personally connected with the meaning of the word, expanded understanding through academic learning, and reflected upon new understandings. While tensions and discomfort about using language and cultural concepts from "outside" one's own ethnic and racial background may still exist, we are encouraged by the idea that pre-service teachers can commit to broadening and embracing understandings of aloha as a meaningful part of their daily classroom practices and lives.

Keywords: culturally responsive pedagogy, place-based education, aloha 


\section{Introduction}

As teacher educators in the multiethnic, multicultural milieu of Hawai'i, we place a high priority on cultural values in our teacher education program. At times feelings of inadequacy and discomfort can plague educators who aspire to incorporate language and cultural concepts in their classrooms (Cutri \& Whiting, 2015). They may feel underprepared or unequipped to use language and cultural concepts which are not theirs but are the legacy of their students or the communities where they teach. Fear of misrepresenting, misusing, and misappropriation of language and culture outside their own experiences may undermine the best of intentions (Gay \& Howard, 2000). Additionally, there are tensions between theoretical ideas that disrupt inequity structures and everyday classroom activities (Pollock et al., 2010). These tensions can lead to avoidance, resistance, or rejection from the very goal that was intended. Even though Hawai' $i$ is known for its diverse cultural context, these challenges still exist. Halagago's (2006) work with teacher education students in a multicultural course which examined social inequities between privileged "non-minorities" and "disadvantaged minorities" in Hawai'i found that "living among diversity in Hawaii made recognition of racism and privilege difficult" (p. 38).

Given these challenges, and tasked with doing a better job of incorporating Hawaiian language, history, and culture into our teacher education curriculum, we were excited at the prospect of being able to access the State of Hawai'i, Department of Education's $H \bar{A}$ framework as the foundation for our one-credit graduate course, "Teaching in Hawai'i's Schools." This framework was created to develop, "the skills, behaviors, and dispositions that are reminiscent of Hawai'i's unique context, and to honor the qualities and values of the indigenous language and culture of Hawai'i" (Hawaii State Department of Education, n.d., para. 1). Nā Hopena $A^{\prime}$ 'o or $H \bar{A}$. Nā indicates a plural, Hopena means outcome, and $a^{\prime} O(H \bar{A})$ means both learning and teaching in the Hawaiian language. It includes six outcomes that are rooted in Hawaiian culture and encompasses values that are universal to all cultures. The English words form the acronym B.R.E.A.T.H.: sense of Belonging, Responsibility, Excellence, Aloha, Total well-being, and Hawai'i.

The first year we focused on each of the outcomes with our pre-service teachers using predetermined descriptors to establish a common starting point; however, this appeared to establish a superficial understanding and a cursory commitment to using $H \bar{A}$ learning outcomes. Some seemed to view it as an intellectual exercise rather than authentic practices, with some resisting and dismissing the $H \bar{A}$ framework based on exclusivity or "only for Native Hawaiians" (having ancestral ties to the indigenous culture, hereafter referred to as Hawaiian). We realized we had to take a different approach with a new group of pre-service teachers and looked to our previous work with in-service teachers and culturally responsive teaching practices (Ebersole, et al., 2016). We recognized that learning through story, making connections with prior experiences, and reflection supported understanding and transformation. We believed that previously identified categories: experiential, academic, and reflective knowledge might help us to deepen cultural understandings (Ebersole, et al., 2015). As we further contemplated the framework, one word emerged: aloha. This led us to wonder: What would happen if we structured a teacher education course around the word aloha? This research is a glimpse into how a teacher educator program offered Hawaiian culture values-based education, through exploring the meaning of one word: aloha. 
The research question that guided this inquiry was: Do pre-service teachers' written reflections indicate a shift in their understanding of aloha?

\section{Aloha}

It is popularly known that the term aloha has multiple meanings. According to Pukui and Elbert (1986) aloha is translated to be love, affection, compassion, mercy, sympathy, pity, kindness, sentiment, grace, charity; greeting, salutation, regards; sweetheart, lover, loved one; beloved, loving, kind, compassionate, charitable, lovable. The word is often thought to be synonymous with Hawai' $i$ and its residents, thereby indicating that an object connected with the word is automatically characterized as something Hawaiian. For years the word has been uttered in expressions of greetings, love, and farewells. In ancestral texts, poetry, and song the practice of aloha adheres closely to the aforementioned translations.

Today we reference authors of the epic myth of the fire goddess Pele and the journey of her heroine sister Hi'iaka and their foresight of poetry, and foretelling inclusion in the narrative. These excerpts of poetry have been considered as actual observations of nature that have been documented in and decorated with story. For the purpose of this paper, the focus is on Emerson's (2005) version of this narrative entitled, Pele and Hi'iaka: A Myth from Hawaii. The following excerpt is an example of language wrapped in observation.

\section{Aloha Oahue}

E huli ana makou i ka aina ma mua aku Kahi a makou e noho ai

Aloha o Maui, aloha e

Aloha o Molokai, aloha e

Aloha o Lanai, aloha e

Aloha o Kahoolawe, aloha e

Ku makou e hele e

o Hawaii ka ka aina

A makou e noho ai a mau loa aku Emerson, 2005

\section{Aloha to the island of Oahu}

we turn to the land before us

the place where we will live

Maui is Aloha

Molokai is Aloha

Lanai is Aloha

Kahoolawe is Aloha

We prepare to travel

Hawaii is our land

Our land where we will live forever...

This excerpt of verse is from one of the most ancient pieces of known Hawaiian myth. The story that surrounds this section of myth is the departure of Pele, the volcano deity, and her family from islands that kept memories of a long journey to her final home on the island of Hawai'i. According to the narrative surrounding this verse, the canoe of this family stopped off on every island to bid aloha before continuing south to the island of Hawai'i. When adhering to this translation and using a literal interpretation of all parts of the word aloha, this story sheds new insight on the definition of aloha. Aloha is made up of alo and hă. Alo is translated into "front, face, presence, to pass." The word ha translates to "breathe, exhale, or to breathe upon" (Pukui \& Elbert, 1986). With the least amount of interpretation and with a literal lens, the word aloha is an action-based term which requires two or more entities exchanging breath in the presence of each. An exchange is required without presumption. When an exchange is required it's done in the presence $(a / o)$ of another entity.

In 1986 George Kanahele conducted a survey amongst the Hawaiian community to identify and rank Hawaiian values. Aloha was mentioned most frequently and ranked the most important (Kanahele, 1986). In the time of growing and peaking tourism, the "Aloha Spirit" became a more desired destiny feature than sandy beaches. In Ohnuma's article, she states that the Hawaii Visitors Bureau's slogan at one time was "Aloha. The more we give, the 
more we've got" $(2008$, p. 372). These factors set the stage for separation of the true meaning of the word aloha originating in ancestral text discussed earlier and the practice of using the word aloha in all aspects of Hawai'i society.

\section{Strengths-Based Education}

In situating the value of aloha in schools, there are established educational practices aligned with this specific island value in some Hawaiian language and culture-based charter schools. Tibbets et al., (2007) state, "Education with Aloha" is education through positive development and affective ideals. Education with Aloha, "focuses first and foremost on creating and maintaining positive relations among all stake-holders through the establishment of a dynamic learning 'ohana (extended family). Like a traditional Hawaiian family, this learning 'ohana practices aloha, aligning with the Hawaiian proverb: Aloha kekahi $i$ kekahi pēlā ihola ka nohona 'ohana (love one another, such is family life)" (Tibbets et al., p. 150).

We frame this study using an educational approach that highlights strengths and acknowledge the "funds of knowledge" marginalized populations bring to school (González et al., 2005). Lopez and Louis (2009) state that strengths-based education is "a philosophical stance and daily practice that shapes how an individual engages the teaching and learning process ... that emphasize the positive aspects of student effort and achievement, as well as human strengths" (p. 1). According to Kana'iaupuni (2004), "Ka'akālai Kū kanaka, strengthsbased approaches employ strategies based on competencies, capabilities, and expertise... From a Hawaiian perspective, these individual capabilities are grounded in the strengths of family and community relationships" (p. 30). Building upon assets from a collectivistic perspective that uses indigenous strengths to encourage positive cultural development (Borrero et al., 2012), we also value the strong ties to place that each individual brings to the learning context (Kawakami,1999).

\section{Place-based Education}

The instructional connection between place-based and indigenous education is foundational. Place is the source of knowledge. Kawagley and Barnhardt (1998) support this by stating that "indigenous knowledge is rooted in the long inhabitation of a particular place which provides lessons to all from educators to scientists" (p. 1). Gruenewald (2003) agrees that place-based education contextualizes learning within specific places and communities. The aim of this method is to ground learning in local phenomenon and student experience (Smith, 2002). Place is a means of perceiving and understanding the world, a micro-world to study the whole (Semken et al., 2017). Place-based education is not a new concept. Prior to the establishment of formal education in Hawai' $i$, one's education is determined by their knowledge of their place (Pukui et al., 1998).

I puni ia 'oe o Ka'u a i 'ike 'ole 'oe ia Palahemo, a'ohe no 'oe i 'ike ia Ka'u

If you have been around $K \mathrm{~K}^{\prime} \mathrm{u}$, and have not seen Palahemo you have not seen $K a^{\prime} u$.

(Pukui, 1983)

The interpretation of this famous saying is: if you don't know the details of your place you don't know your place. Knowledge of place and being connected to place are fundamental to place-based education and foundational to culturally relevant and culture-based education in Hawai'i. 
The following section provides a very brief overview of culturally relevant and culturebased education in Hawai'i to distinguish between Hawaiian language and culture focused schools and efforts to establish the study of Hawaiian culture, history and language within the context of mainstream public schools in Hawai'i.

\section{Culturally Relevant and Culture-Based Education in Hawai $i$}

Since the State Constitution was amended in 1978, there have been a number of initiatives to establish, Hawaiian culture, history and language in Hawai'i's public school system (Benham \& Heck, 1998; Office of Hawaiian Affairs Research Division, 2017). Widely cited studies conducted as part of the Kamehameha Early Education Program (KEEP) identified effective culturally appropriate practices in an education lab context and mainstream educational contexts serving communities with a large population of native Hawaiian children (Au, 1980; Au \& Mason, 1981; Gallimore \& Tharp, 1976; Jordan, 1985; Tharp \& Gallimore, 1988; Tharp et al., 2007). More recently, a growing body of research on successful culturally relevant and responsive teaching and assessment practices in Hawaiian language medium and Hawaiian culture-based charter schools emerged (Kana'iaupuni \& Kawai'ae'a, 2008; Keehne et al., 2018; Schonleber, 2007; Tibbets et al., 2007). Additionally, current research to highlight culturally sustaining pedagogical approaches which seeks to perpetuate, foster and sustain linguistic, literate, and cultural pluralism (Paris, 2012; Paris \& Alim, 2017) and culturally revitalizing pedagogies which recognizes indigenous peoples legacies of colonization and fight towards linguistic and cultural survival (McCarty \& Lee, 2014) is being conducted in contemporary Hawaiian schools (Kaomea et al., 2019). Much of this work is respected and recognized in the context of Hawaiian language and cultural revitalization to serve primarily Hawaiian or part-Hawaiian students and thus, perhaps perceived by some as only applicable to that population of students.

Research on the use of culture-based education approaches across the different types of school contexts in Hawai'i found, "regardless of school type, teachers from many different cultural backgrounds recognize the advantages of cultural relevance, reporting a range of culturally relevant teaching practices that help them connect with their students in meaningful ways" (Kana'iaupuni \& Ledward, 2013, p. 154). Additionally, Hawaiian culturebased education use "is not exclusive to a single ethnic group" (Kana'iaupuni et al., 2017, p. 328S). Although much progress has occurred, changing attitudes and beliefs toward culturally relevant and responsive education and the pursuit to Hawaiian knowledge, values and stories within Hawai'i's mainstream school system for all students continues to be challenging today (Kawakami, 2004).

\section{Positionality}

It is important to note that our positionalities as female Hawaiian cultural practitioner and scholar with ancestral knowledge and as fourth generation female Japanese American uniquely influenced our perspectives. We believe our personal experiences living in Hawai' $i$ and our individual racial and cultural identities provided a degree of historical and cultural knowledge which shaped our teaching practices and how the pre-service teachers perceived us as course instructors. For one course instructor, as a respected Hawaiian language and cultural practitioner, this curricula is not viewed as separate entity, but rather a lived experience. For the other course instructor her own apprehension of misappropriating or 
misrepresenting the sacred nature and depth of Hawaiian cultural values was present in teaching and writing this research.

\section{Method}

A qualitative phenomenological approach was used for this inquiry because it lends itself to a phenomenon to be explored, in terms of a single concept or idea, with a group of individuals who have all experienced the phenomenon (Creswell \& Poth, 2018). This phenomenological study focused on the cultural value of aloha with a group of pre-service teachers after experiencing a one-credit teacher education course entitled, "Teaching in Hawai i's Schools." The course is the introductory course in a graduate level teacher education program. It begins in the summer session and is offered over three-days.

\section{Participants}

All pre-service teachers were enrolled in a teacher preparation program which included a traditional student teaching component at the end of the year. Twenty-two of a total of 23 pre-service teachers enrolled in the program consented to participate in the study after the course was completed. Of the 22 teachers, 12 were licensed as secondary teachers and 10 were licensed as elementary teachers. There were 12 female and 10 male participants representing multiple racial and ethnic groups. Eighty-two percent of the pre-service teacher participants in the study reported they were born and raised or raised in Hawaii. Forty-one percent of the participants self-identified with a single racial group - Asian, Native Hawaiian and Pacific Islander, White. Fifty-nine percent of the participant group self-reported mixed racial and ethnic identities including American Indian, Asian, Native Hawaiian and Pacific Islander, White, and White Hispanic. According to the U.S. Census data (Hawaii Department of Business, Economic Development and Tourism, 2019) population estimates $24.2 \%$ in Hawai'i have two or more races which is much lower than the participant group. Thirty-six percent of the participant group self-identified as Hawaiian or part-Hawaiian while Hawai' $i$ State Census data indicates 35.3\% Native Hawaiian and Other Pacific Islander alone or in combination reside on Hawai'i island. The Hawai'i Department of Education (2018) reports $10.1 \%$ Hawaiian or part-Hawaiian teachers. The percentage of Hawaiian and part-Hawaiians in the participant group is comparable to the Hawaiian and Other Pacific Islander population on the island but well above the percentage of Hawaiian or part-Hawaiians teachers in the state. As as a whole, the participant group includes a higher percentage of individuals of mixed race and fall below the percentage of Asian only and White only teacher population and population of Hawai'i in general.

\section{Procedure}

The university course began with an exploration of the concept of aloha through story. On the first day of class, pre-service teachers brought in a picture of the word, aloha which served to awaken their personal understanding of its multiple meanings. As part of the storytelling that occurred, we shared our personal connection as high school classmates and how our relationship developed over time with research collaborations and co-teaching opportunities. Over the course of the first day, we built upon our personal understanding and meanings of aloha" through sharing stories with the pre-service teachers. We asked them to recall experiential depictions of aloha or "stories of aloha." Our intention was to build upon personal knowledge and experiences to establish a deeper relationship with the value of 
aloha. Once they began to get to know each other through discussion of the word aloha, we provided an overview of the Hawai'i Department of Education Nā Hopena A'o or $H \bar{A}$ framework and announced we were going to concentrate upon one of the outcomes, "sense of aloha." We shared an excerpt on "Aloha is our Intelligence" from Meyer's (2010) video "an Introduction to "Indigenous Epistemology'." The day ended with a discussion of the many images and meanings of aloha within larger society and pre-service teachers were introduced to the literal meaning of the word alo - (face-to face), and ha - (breath). After discussion, they completed Written Reflection \#1 as the final activity for the day.

On the second day of the class, one course instructor lectured about the literal meaning of the word aloha and brought in the ancestral story of Pele and Hi'iaka. She provided an excerpt of aloha within the story and later had the pre-service teachers interpret aloha within the chant. Later that day, we traveled to Mokuola (Healing Island), a small island near the university for a field trip to practice learning through observation. The goal for this experience was for the pre-service teachers to observe and take note of details of nature lending a more concise observation of nature, thus, observing with presence and intentionality. As the final activity for the day, they completed Written Reflection \#2. For homework pre-service teachers read academic articles on culture and cultural relevance in education and completed written responses.

On the third day of class, the pre-service teachers discussed the articles and interviewed each other about their personal and cultural identities. Through the interview process they interpreted the aloha they saw in their partners and themselves. The prompt for Written Reflection \#3 was completed at the end of the third and final day of class. A few days later they submitted their personal and cultural identity story as a final product for the course.

\section{Data Collection}

The data set included pre-service teachers' personal written reflections completed at the end of each day of the course and a questionnaire completed 10 months post-course completion, after pre-service teacher's student teaching experience. Each of the three written reflections were handwritten and approximately half a page to one page in length and two to three pages in total length per each of the 22 participants. Four months after the course was completed, pre-service teachers who enrolled in the course were asked for consent to participate in the study. Six months later responses on the post-course questionnaire were collected and written reflections of those who agreed to participate in the study were accessed. There was no pre-course questionnaire. The prompts and questions for each are listed below.

Written Reflection \#1 prompt: How is having a sense of aloha part of who you are?

Written Reflection \#2 prompt: Has your perspective of aloha shifted?

Written Reflection \#3 prompt: How might you bring a sense of aloha into your classroom?

The post-course questionnaire included the following questions: (1) Think back to the very first course in the program, ED 650, Teaching in Hawai'i's Schools, what do recall about the course and your experience? (2) How did your experience in the course impact your perspective such as your relationships, as you progressed through the program? (3) If aloha is important to you, what does it look like as a value in your classroom? (4) Aloha may be seen as representing the culture of Hawai' $i$. It is multi-faceted and there are many layers to its meanings. Through discussion people defined aloha as: an exchange of breath, reciprocity, 
presence, compassion, understanding, empathy, accountability. Which of these words resonate with who you are and why? (5) How will you use aloha as you move forth in your career? Participant responses to the questionnaire were about one page in total length.

\section{Data Analysis}

A phonomenological method of analysis was used (Creswell \& Poth, 2018). Both researchers read through all the written reflections and questionnaire data and separately developed a list of significant statements to create initial meaningful categories. Researchers met to compare initial statements and agree upon categories. Written data statements were coded manually into categories. The categories were then grouped to identify broader units or themes. Researchers met several times over the course of a year to analyze data.

Individual written statements were re-read, counted by category and aligned with the themes listed in Table 1. Researchers discussed themes to identify what the participants experienced with respect to their understandings of aloha and reflected upon how the setting and context influenced the experienced phenomena. Individual responses were later entered into an excel spreadsheet, counted, and color coded by themes as an additional method to cross-check data for accuracy and ensure all participant responses were included.

\section{Findings}

As a result of qualitatively analyzing their written reflections and post-course questionnaire, three patterns emerged to reflect the shifts in their understanding of the word aloha: (1) Common Understandings of Aloha; (2) Methods for Activating Aloha; and (3) Sustainable Practices. The categories which defined each of the themes is shown in Table 1 and explained sequentially in this section.

Table 1: Understandings of Aloha

$\begin{array}{lll}\text { Data Source } & \text { Theme Category }\end{array}$

Written

Reflection \#1

(Day 1)

Common Knowledge

Understandings of Aloha

Written Methods for Activating Aloha Reflection \#2

(Day 2)
- Kindness \& Love (10)

- Appreciation \& Openness (5)

- Compassion \& Empathy (1)

- Exchange (6)

- Connecting with the 'Āina (6)

- Being Present and Experiencing a Reciprocal Exchange (10)

- Being Consciously Aware and Seeing Aloha Everywhere (6)

Common Knowledge

Understandings of Aloha,
- Care and Compassion (3) 


\begin{tabular}{lll} 
Data Source & \multicolumn{1}{c}{ Theme } & \multicolumn{1}{c}{ Category } \\
\hline Written & & \\
Reflection \#3 & Methods for Activating Aloha, & \\
(Day 3) & Sustainable Practices & - Having Respectful Relationships (11) \\
& & - Practicing Aloha as a Way of Being (8)
\end{tabular}

$\begin{array}{ll}\text { Post-Course } & \text { Common Knowledge } \\ \text { Questionnaire } & \text { Understandings of Aloha, } \\ \text { (21 responses } & \text { Methods for Activating Aloha, } \\ \text { returned) } & \text { Sustainable Practices }\end{array}$

Note. 22 total pre-service teacher participants, number in parentheses indicates number of participant responses in each category.

\section{Written Reflection \#1- Common Understandings of Aloha}

Pre-service teachers' initial responses were based on the personal meanings they brought to class and described understandings of aloha they saw within themselves at the end of the first day of instruction. Qualitative data analysis from their written reflections after Day 1 were grouped under the theme: Common Understandings of Aloha which are in alignment with some of Pukui and Elbert's (1986) translated words or common definitions of aloha that are promoted by the tourist industry and perpetuated in textbooks written for Hawai'i's youth (Kaomea, 2006). Within that theme there were three categories: (1) Kindness and Love; (2) Appreciation and Openness; (3) Compassion and Empathy. The fourth category (4) Exchange incorporated the literal interpretation of the word aloha. Each pre-service teacher response is labeled: $\mathrm{E}$ for elementary or $\mathrm{S}$ for secondary to distinguish between elementary and secondary pre-service teachers and is assigned a number to indicate separate individual responses.

\section{Kindness and Love}

There were ten pre-service teachers whose initial responses implied aloha was expressed through showing kindness and by helping others. Pre-service teacher E8 wrote, "I was always taught to help others when needed and be kind to everyone." E3 stated, "Aloha to me is about showing love, helping others, and being positive." According to S12, "It encompasses kindness, respect, love, friendship, warmth, and generosity." They expressed the idea that through helping others they could show aloha, which meant kindness and love. Their written reflections seem to indicate that the common belief that aloha is a word that is associated with positive feelings and generosity.

\section{Appreciation and Openness}

Initial responses from five pre-service teachers demonstrated aloha as appreciation for self and being open to others. Pre-service teacher E4 noted, "Being able to appreciate people from all different walks of life is having a sense of aloha." E5 added, "It's (Aloha is) 
more than just hello and goodbye ... being open, on a bigger scale that's more than just interacting with tourists. Open to new ideas, to people, to new beginnings and change." E9 explained, "Having a sense of aloha as an individual allows me to open my mind to the diverse culture we have here." Thus, at the beginning of the class pre-service teachers understood having aloha was being open to appreciate and accept diversity of others.

\section{Compassion and Empathy}

The initial response for one of the pre-service teachers fell within the sub-category Empathy and Compassion. In the first written reflection pre-service teacher E6 shared:

Aloha has different meanings, but I define aloha by having empathy. My sense of aloha is demonstrated by having empathy for not only people, but the environment as well. Being aware of the feelings of others and how I affect them is an important part of who I am. This means showing compassion towards others, spreading happiness when possible and putting myself into another person's shoes.

Hence, this pre-service teacher communicated aloha could be shown for others by showing compassion and having empathy for others.

\section{Exchange}

After the literal meaning of aloha was introduced at the end of Day 1 , six of the preservice teachers' responses demonstrated that their understanding of aloha began to expand. Pre-service teacher E2 wrote, "In class I learned more about the literal meaning of aloha and never thought about it as an exchange with a person, place, or thing. Now I am more aware of where I am in the moment and how I can make an exchange filled with the true essence of ALOHA." E10 shared, "I define aloha as a healthy and loving exchange with places, people, animals, etc.around me." After hearing a new definition for the word aloha their understanding of the word aloha began to change.

At the end of the first day of class, 16 of 22 pre-service teachers' reflections were grouped under the first three categories: (1) Kindness and Love; (2) Appreciation and Openness; (3) Compassion and Empathy. These categories were labeled as Common Understandings which are often associated with positive feelings and generosity commonly accepted by the general population often promoted by the tourist industry in Hawai i. Prior to writing their first reflection, pre-service teachers were introduced to the interpretation of the word aloha and six out of 22 or $27 \%$ of them used parts of the literal interpretation in their written reflection which fell under the category 4) Exchange. After the first day, understandings for $73 \%$ aligned with Common Understandings of aloha and $27 \%$ of them included parts of the literal interpretation of the word which had been introduced to them that day.

\section{Written Reflection \#2 - Methods for Activating Aloha}

At the end of the second day of class, written responses indicated 16 out of 22 or $73 \%$ of participants conveyed they experienced a shift in their understanding of aloha. Five participants responded their understandings of aloha did not "shift," and instead used the following words to describe their understanding of aloha: "expanded," "strengthened," "influenced," "renewed," and "broadened." One implied he brought a deep understanding of aloha through previous language study so it did not shift much. S3 reflected, "To be able to dig deeper into its meaning and to learn about the roots of the word has really given me a 
new angle to think of aloha in." Thus, for a number of them they felt they had a firm understanding and the class helped them to think of aloha in new ways. Their descriptions show they began to define methods to activate or "do" aloha. Data were categorized under the theme: Methods for Activating Aloha and included three categories: (1) Connecting with the 'Āina; (2) Being Present and Experiencing a Reciprocal Exchange; and (3) Being Consciously Aware and Seeing Aloha Everywhere.

\section{Connecting with the 'Āina}

Six of the pre-service teachers' responses suggested that going into the natural environment created a space where they felt a greater relationship with the 'âina (land). Preservice teacher S4 wrote, "I was brought up with the mentality of respecting the land but after today's experience I feel an even greater connection to the 'aina." S7 found, "My perspective of aloha has shifted because after this visit I feel it has a stronger connection to the land ... I believe this activity helped me understand how aloha relates to a symbiotic relationship between man and the land." S1 expressed the experience at Mokuola allowed her to, "take a moment to be able to feel and connect with the land." The trip to Mokuola allowed them to connect with the land and enhance their sense of place.

\section{Being Present and Experiencing a Reciprocal Exchange}

In Written Reflection \#2, ten out of 22 responded aloha can be about being present and experiencing an exchange with nature or having an enhanced relationship with the 'aina. S8 reflected, "Part of what we learned today was that Aloha is about being present. It's about being aware of your surroundings and being in a place not just physically but mentally and emotionally as well." S5 responded that the field trip exercise at Mokuola, "was an opportunity to immerse ourselves in nature and focus on ourselves while being in the present state." S11 expressed:

Going to Mokuola today was an act of aloha and in the sense that we went there with the intentions of being in the presence of the place to exchange our energies. We all went with our unique perspectives and gave our attention and willingness to observe the elements that revealed themselves at Mokuola...sometimes we go about our lives moving too fast to really pay attention to the little details that are revealed when you slow down and allow yourself to be more present. If we embodied this form of aloha more often, I feel like we would be able to develop a deeper connection with our environment/surroundings. (Written Reflection \#2)

Pre-service teachers described being able to activate aloha through being present and having an exchange with the natural environment. E10 stated, "Aloha actually means to have a face-to-face meaningful exchange with something else. . . by being present, I allowed myself to have that meaningful exchange of Aloha with the place." E1 wrote, "The exchange can be described as the attitude or feelings you bring in that will therefore be mirrored and reciprocated back. I felt that after what I experienced during today's activity aloha can be viewed as a reciprocal process." Thus, by being present with the environment they were able to experience or reciprocate aloha with the natural environment and activate their sense of aloha. After the observation activity which required them to sit, silently observe patterns in nature, they were able to be present and experience an exchange of energy with the environment. 
Ebersole, M. \& Kanahele-Mossman, H., Broadening Understandings of the Cultural Value of Aloha in a Teacher Educator Program

\section{Being Consciously Aware and Seeing Aloha Everywhere}

Six out of 22 pre-service teachers' responses revealed that after experiencing aloha with nature, there was an enhanced awareness. E7 reflected, "I don't believe that my perspective has shifted but rather broadened to include ALL things." S2 concluded, "My perspective on aloha is that it is everywhere --- we live it, we feel it, we are it." After their experience at Mokuola and through reflection, some pre-service teachers became consciously aware of seeing aloha everywhere which was a method for activating their sense of aloha.

At the end of the second day of class and going to Mokuola to conduct observations of nature, $73 \%$ of the pre-service teachers wrote that their understandings of aloha had shifted and $23 \%$ reflected their understandings did not shift, but rather used words such as broadened, expanded, strengthened, enhanced, and renewed which seem to indicate growth or constructing new understandings based upon existing knowledge. One pre-service teacher indicated that it did not shift much due to expansive previous knowledge and experience with Hawaiian language and culture. The place-based experience on Mokuola seemed to support Methods for Activating Aloha which included connecting with the `aina, being present and experiencing a reciprocal exchange with nature, and being consciously aware of seeing aloha in their lives.

\section{Written Reflection \#3 - Sustainable Practices}

Responses for Written Reflection \#3 fell under two previously identified themes, Common Knowledge Understandings of Aloha and Methods for Activating Aloha and a third theme which emerged, Sustainable Practices. Under this theme, there was an additional category: Practicing Aloha as a Way of Being. Three out of 22 pre-service teachers described aloha in the classroom as being caring and compassionate toward their students. This was categorized under the theme, Common Knowledge Understandings of Aloha. Eleven out of 22 responses described how they envisioned aloha in the classroom as Having Respectful Relationships with their students. S6 explained, "I plan to use aloha through the relationships that are created amongst my classes and my coworkers." S12 wrote she would use aloha for, "Building trust and respect between students and myself to provide for teaching and learning and for exchange between students and myself." Many of them perceived aloha as a way to guide them in their relationships with others at school. This category fell under the theme, Methods for Activating Aloha.

\section{Practicing Aloha as Way of Being}

Responses for eight out of 22 of them indicated they understood practicing aloha as a way of being. Pre-service teacher E10 described aloha as "the way I engage with the world." S9 claimed, "Everything I do is aloha." This implied they knew how to activate aloha and would be able to practice it as a part of who they are as they engage with the world. This was categorized under the theme, Sustainable Practices which will be described in more detail below.

\section{Post-Course Questionnaire - Sustainable Practices}

At the end of student teaching, 21 out of 22 participants completed the post-course questionnaire. Responses for question 5 (How will you move forth in your career?) are presented here. After student teaching, responses showed six out of 21 perceived aloha as having empathy or showing understanding and compassion to others which was categorized 
as Common Knowledge Understandings of Aloha. For them, their firmly held beliefs about understanding aloha as compassion and empathy were reflected in their responses. Five out of 21 of the pre-service teachers' responses suggested they understood Methods for Activating Aloha, such as using aloha as a reciprocal exchange that takes place.

For 10 out of 21 pre-service teachers, aloha was not only a concept to be utilized in their classroom, but it was seen as a sustainable practice for daily life. E7 stated, "Aloha has grounded me in realizing what is important and has guided me through difficult experiences and decisions. . It will guide my actions each day. It will set the standard for my attitude going forward." S11 viewed aloha, "As a lens through which to navigate the journey" and S10 stated, "I will use aloha as a part of myself." E8 claimed, "I will use aloha every day in my career" and S12 commented, "Living in Hawaii, it's a value that I can identify with - not just here but wherever I may be." These statements show that aloha can be a practice to guide decisions whether it be in their careers or whereever they go. Others, like E9, felt the sense of duty of aloha. He described aloha as, ". . . an engaging obligation in life." These responses indicate their understandings of aloha include a commitment to sustaining it as a practice which can guide their decisions and actions moving forward in life.

Therefore, over time pre-service teacher understandings of aloha shifted from a familiar concept which was broadened to include actions that described methods for activation, to being present or having a reciprocal exchange with the 'aina or with another person. This new understanding of aloha led to methods for bringing aloha to life. Descriptions of aloha also implied that pre-service teachers saw aloha as a practice, a way of being vs. concepts are applied within certain contexts. For some, it became a perspective and a lens through which they viewed the world.

\section{Discussion}

Our earlier work examined in-service teachers' understandings and perspectives on culturally responsive pedagogy (Ebersole, et al., 2016). Based on previous research, we identified three categories: experiential, academic, and reflective knowledge to organize the types of knowledge which can support transformation for culturally responsive teaching (Ebersole, et al., 2015). We believe these three types of knowledge contributed to a transformative shift in participants' understanding aloha and use this as a framework to discuss our findings.

\section{Start with the Familiar to Build upon Personal and Experiential Knowledge}

By beginning our teacher education program framed around the meaning of the word aloha, which can be a greeting, hello or welcome, we sent pre-service teachers the implicit message that we welcomed everyone into the learning context. Aloha is also a word that most people are familiar with, including visitors and newcomers. It is a word that is often synonymous with Hawai'i and can be perceived as part of Hawai'i's identity based upon its nickname alone, "The Aloha State." Images of the word itself are commonly viewed and used in popular media and culture, thus, the pre-service teachers were familiar with the word and understood some of its many meanings. At the beginning of the class, we asked them to take notice of the word aloha around them and share personal stories which might depict its meaning. In this way, we tapped into their experiential knowledge base legitimizing personal meanings they brought to the learning context. Their experiential knowledge in this context reflects lived knowledge or knowledge teachers gain through personal experiences. It is 
embedded in practice and builds on "funds of knowledge" (Moll et al., 1992) or lived cultural experiences, which can legitimize the local knowledge teachers bring to a particular context. By recognizing and valuing lived knowledge and cultural experiences we built upon the strengths of individuals and communities and focus on their assets and potentials (Kana iaupuni, 2005 Tibbetts et al., 2007).

Although the word aloha conjures meanings of love, peace, and compassion for many residents in Hawai' $i$, the concept of aloha has been exploited for commercial and political purposes over time (Kaomea, 2006; Ohnuma, 2008). We acknowledged and recognized this concept of aloha with pre-service teachers. Additionally, before asking them to engage in the academic exercise of interpreting ancestral stories they were explicitly asked to "suspend their former meanings of the word." This acknowledgement and request may have been an important step after experiential knowledge had been legitimized.

\section{Interpret Stories and Explicit Teaching to Construct Academic Knowledge}

Academic knowledge is often gained through reading and discussing seminal articles within the field of education. This knowledge-for-practice (Cochran-Smith \& Lytle, 1999) such as subject matter, theoretical framing, pedagogy, and instructional strategies includes knowledge, interpretative frameworks, beliefs, and attitudes needed to effectively teach diverse populations (Cochran-Smith et al., 2003). The telling of indigenous ancestral stories from Hawaiian culture providing direct academic knowledge through storytelling. Pre-service teachers interpreted how aloha was exemplified in the story as a means to deepen or enhance understanding of the meaning of the word aloha. The process of deconstructing implicit meanings of aloha within the context of ancestral stories may have provided preservice teachers with deeper academic knowledge and greater confidence in understanding the depth and layers to the meaning of aloha. They gained academic knowledge about aloha through direct instruction about the literal meaning of the word aloha and the Na Hopena $A^{\prime} O$ framework and through viewing videos having discussions about aloha.

\section{Experience Aloha through Place-based Learning}

In addition to the academic knowledge built through implicit and explicit instruction, the pre-service teachers experienced aloha to enhance understandings. We put forth a placebased learning experience for them to reconstruct what the meaning of aloha meant to them, contributing to their experiential knowledge. Many mentioned how they experienced an exchange or "act of aloha" through the place-based learning experience on Mokuola. An important outcome of this experience was to establish ownership of place. Gruenewald (2003) confirms that, "place based pedagogies are needed so that the education of citizens have direct bearing on the well-being of the social and ecological places people inhabit" (p.3). In this respect the field trip to Mokuola was the basis of knowing aloha and for knowing Hawai'i. For the purpose of this research it is important that reference is made to ancestral text.

Aloha Au o Mahiki

Aloha au o Mahiki

My aloha of Mahiki

Me he ku ana la na ke Ko'iula

like the steadfast of the red hued rainbows

(Pele and Hiiaka, 1909)

Mahiki, another well-known place on the island of Hawai $i$, is a very large wet forest. The two lines display a mutual-equal recognition of presence for the composer and the rainbow 
frequently seen in this forest. This experience between observer and place is the knowledge forming lesson. Dewey (1938) eloquently confirms this by stating, "That environment steadily expands by the momentum inherent in the experience itself" (p.74). Dewey (1938) goes on to stress that this occurs outside of scholastic instruction. This is the leveling of aloha and placebased pedagogy. Teachers and thereby students turn to nature and phenomena immediately around them as their foundational curriculum. Through the lens of their place they can examine other places and gain new knowledge (Smith, 2002).

By incorporating multiple educational practices such as close observation of nature, discussion, and self-reflection, pre-service teachers reconstructed their understanding of the meaning of aloha. Each participant came to the learning context with unique and different perspectives about the meaning of aloha and with new learning experiences they reconstructed meanings and strengthened academic and experiential knowledge.

Throughout this study, participants associated the meaning of aloha with being kind, helpful, and compassionate which connects with positive, happy feelings and emotions preservice teachers brought with them. After the first day, some of them shared they understood aloha as empathy and others began to see it as an exchange. After participants experienced the exchange with the natural environment, they shared powerful new insights. They mentioned ways to "activate" aloha such as "being present" to experience the reciprocal exchange.

It can be assumed that exchange and reciprocity are the same but with the Hawaiian ancestral context, reciprocity is not limited to an exchange. There is a great deal of rigor in terms of reciprocity that goes into aloha. When it is a reciprocal exchange there may be something that is given in return, a mutual agreement or an obligation that binds two parties equally; thus, to experience aloha within this contextual definition, one must be aware of one's participation with nature and relation to environmental surroundings. The reciprocation the environment gives, and one receives, shows in one's actions. This reflects the reciprocal accountability that goes with aloha. Additionally, pre-service teachers needed to be open to this reciprocal exchange to be able to see and experience it. Empathy when defined as being able to understand someone else's feelings, doesn't require for one to be open enough for reciprocation. That's where rigor in aloha comes in and there is a limitation of empathy. There is an intangible - don't need to "know it" but need to "feel it" experience associated with the meaning of aloha. Learning in places of significance supports students in developing knowledge of themselves, their culture, and their history (McVittie et al., 2020). Thus, the exchange pre-service teachers experienced with the natural environment at Mokuola was significant and helped to shift their understanding of aloha.

\section{A Process of Connection through Self-Reflection: From Articulation to Activation to Creation of a Blueprint}

Pre-service teachers went beyond merely articulating what aloha meant personally. They qualified what aloha "looks like" and set a standard based upon what they knew to be the meaning of aloha. They activated aloha by being present and experiencing it in nature, then consciously recognized it through self-reflection. Through this process of connection, they could internalize and feel aloha differently than previously experienced. When some of the pre-service teachers shifted to understanding aloha as a concept to a "way of being" or a practice, it became a lens through which they could view the world. For those who perceived aloha as a practice, they could begin to construct a blueprint or perhaps a vision for what 
aloha might look like as a value or expectation in their classrooms. Aloha became more than a word and through self-reflection they broadened understanding constructing a blueprint for how to interact with nature, with each other, and in their lives.

\section{Conclusion}

\section{"Permission" to Use Cultural Concept?}

During the first year of implementing Nä Hopena A'o we treated the outcomes and values like standards and objectives, deconstructing each one and explaining how it might be used in classrooms. By immersing ourselves in the meanings and multiple layers of one particular outcome or value, it opened up an avenue for greater understanding and a transformational shift from common understandings to a way of being or a practice. This leads us to believe as teacher educators, we should question how we address cultural values and frameworks within the classroom. Perhaps, instead of approaching the Nā Hopena $A^{\prime} O$ $(H \bar{A})$ framework as an academic exercise, we should structure culture-based and place-based experiences to ensure "learning includes engagement in culturally significant interactions and activities through Hawaiian ways of knowing" (Kawakami, 1999, p. 28). In this context learning focused on: (1) uncovering deeper meanings of aloha that honored the prior knowledge and experience pre-service teachers brought, (2) engaging in place-based educational activities and exchange with the natural environment, (3) promoting academic knowledge of aloha through deconstructing ancestral stories, and (4) providing pre-service teachers time and space to self-reflect upon personal knowledge and experiences.

At the onset of the class, aloha was a familiar concept which might be used casually and informally by pre-service teachers. We acknowledge that some of them may have come to the class open and willing to embrace the cultural value of aloha as a sustained practice yet, as we analyzed the data we also began to question: In order to feel comfortable with using Hawaiian cultural values, do pre-service teachers need implicit and/or explicit permission from a trustworthy source to bring Hawaiian cultural knowledge into the classroom? Could academic, experiential and reflective knowledge serve as a means for granting permission to use other cultural values in the classroom? We hope to use these questions to reflect upon and guide us in future inquiries.

In this research inquiry we believe our positionalities provided both strengths and limitations. Our personal beliefs, experiences, and practices were brought to this experience and reflect our own praxis unique to ourselves and this place and with our pre-service teachers. We acknowledge it may be challenging to activate values which may be tied to fears and perceived institutional barriers situated within a larger values system; however, we strongly believe pre-service teachers may be supported to incorporate cultural values within their own classroom contexts when they see or experience a direct connection and expanded understanding of the value.

This study investigated pre-service teacher change in articulation of the word aloha. It demonstrates how pre-service teachers enrolled in a mainstream teacher education program written responses indicated shifts in understanding the word to reflect the integrity of the translation of aloha as originating in Hawaiian ancestral text. While tensions and discomfort about using language and cultural concepts from "outside" one's own ethnic and racial background are common, we are encouraged by the idea that they can commit to broadening understandings of and embracing an expanded understanding of aloha as a meaningful part of their daily classroom practices and lives. 
Ebersole, M. \& Kanahele-Mossman, H., Broadening

Understandings of the Cultural Value of Aloha in a Teacher Educator Program

\section{References}

Au, K. H. (1980). Participation structures in a reading lesson with Hawaiian children: Analysis of a culturally appropriate instructional event. Anthropology \& Education Quarterly, 11(2), 91-115. https://doi.org/10.1525/aeq.1980.11.2.05x1874b

Au, K., \& Mason, J. (1981). Social organizational factors in learning of reading: The balance of rights hypothesis. Reading Research Quarterly, 17(1), 115-152. doi: 10.2307/747251

Benham, M., \& Heck, R. (1998). Culture and educational policy in Hawai' i: The silencing of Native voices. Lawrence Erlbaum Associates, Inc.

Borrero, N., Yeh, C., Cruz, C., \& Suda, J. (2012). School as a context for "othering" youth and promoting cultural assets. Teachers College Record, 114 (2), 1-37.

Cochran-Smith, M., \& Lytle, S. L. (1999). Relationships of knowledge and practice: Teacher learning in communities. Review of Research in Education, 24, 249-305. https://doi.org/10.3102/0091732X024001249

Cochran-Smith, M., Davis, D., \& Fries, K. (2003). Multicultural teacher education, In J.A. Banks \& C.A. Banks (Eds.), Handbook of research in multicultural education (2 ${ }^{\text {nd }}$, ed., pp. 931975). Jossey-Bass.

Creswell, J., \& Poth, C. (2018). Qualitative inquiry and research design: Choosing among the five approaches (4th ed). Sage.

Cutri, R. M., \& Whiting, E. (2015). The emotional work of discomfort and vulnerability in multicultural education. Teachers and Teaching, 21(8), $1010-1025$. https://doi.org/10.1080/13540602.2015.1005869

Dewey, J. (1938). Experience and Education. McMillan.

Ebersole, M., Kanahele-Mossman, H., \& Kawakami, A. (2015). Teaching through story: Using narratives in a graduate ethnicity course. WOW Stories, 4(9), http://wowlit.org/online-publications/stories/v5-i2/

Ebersole, M., Kanahele-Mossman, H., \& Kawakami, A. (2016). Culturally responsive teaching: Examining teachers' understandings and perspectives. Journal of Education and Training Studies, 4(2), 97-104.

Emerson, N. (2005). Pele and Hiiaka: A Myth from Hawaii. Edith Kanakaole Foundation.

Gallimore, R., \& Tharp, R. (1976). An overview of research strategies and findings (1971-1975) of the Kamehameha Early Education Program. Technical Report \#66. https://files.eric.ed.gov/fulltext/ED158865.pdf

Gay, G., \& Howard, T. (2000). Multicultural teacher education for the 21st century. The Teacher Educator, 36(1) 1-16. https://doi.org/10.1080/08878730009555246

González, N., Moll, L., \& Amanti, C. (2005). Funds of knowledge: Theorizing practices in households, communities and classrooms. Lawrence Erlbaum Associates.

Gruenewald, D. (2003). The best of both worlds: A critical pedagogy of place. Educational Researcher, 32(4), 3-12.

Halagago, P. (2006). Questioning the aloha in a multicultural teacher education course. Asia Pacific Journal of Education, 26(2), 37-50.

Hawaii State Department of Education. (n.d.). Nā Hopena A'o $(H \bar{A})$. http://www.hawaiipublicschools.org/TeachingAndLearning/StudentLearning/Hawaiian Education/Pages/HA.aspx

Hawaii Department of Business, Economic Development and Tourism. (2019). Census. Latest population estimate data. Hawaii population characteristics. 
https://census.hawaii.gov/wp-content/uploads/2020/06/Hawaii-Population-

Characteristics-2019.pdf

Hawaii Department of Business, Economic Development and Tourism. (2018). Research and Economic Analysis. Section 3 - Education. https://dbedt.hawaii.gov/economic/databook/2018-individual/_03/

Jordan, C. (1985). Translating culture: From ethnographic information to educational program. Anthropology \& Education Quarterly, 16(2), 105-123. https://doi.org/10.1525/aeq.1985.16.2.04x0631g

Kanahele, G. (1986). Kū Kanaka:Stand tall a search for Hawaiian values. University of Hawaii Press.

Kana'iaupuni, S. (2004). Ka'akālai Kū Kanaka: A call for strengths-based approaches from a Native Hawaiian perspective. Educational Researcher, 34, 32-38. https://doi.org/10.3102/0013189X034005032

Kana'iaupuni, S., \& Kawai'ae'a, K. (2008). E lahoe mai na wa'a: Toward a Hawaiian indigenous education teaching framework. Hülili: Multidisciplinary Research on Native Hawaiian Well-Being, 5, 67-90. https://files.eric.ed.gov/fulltext/ED523184.pdf

Kana'iaupuni, S., \& Ledward, B. (2013). Ho'opilina: The call for cultural relevance in education. Hülili: Multidisciplinary Research on Native Hawaiian Well-Being, 9, 153-204.

Kana'iaupuni, S., Ledward, B., \& Malone, N. (2017). Mohala i ka wai: Cultural advantage as a framework for indigenous culture-based education and student outcomes. American Educational Research Journal, 54(1S), 311S-399S. https://doi.org/10.3102/0002831216664779

Kaomea, J. (2006). A curriculum of aloha? Colonialism and tourism in Hawai'i's elementary textbooks. Curriculum Inquiry, 30(3), 319-344. https://doi.org/10.1111/03626784.00168

Kaomea, J., Alvarez, M. B., \& Pittman, M. (2019). Reclaiming, sustaining and revitalizing Hawaiian education through video-cued makawalu ethnography. Anthropology \& Education Quarterly, 50(3), 270-290. https://doi.org/10.1111/aeq.12301

Kawagley, A. O., \& Barnhardt, R. (1998). Education indigenous to place: Western science meets native reality. Ecological Education in Action, 117-140 http://ankn.uaf.edu/Curriculum/Articles/BarnhardtKawagley/EIP.html

Kawakami, A. (1999). Sense of place, community, and identity. Education and Urban Society, 32(1) 18-40. https://doi.org/10.1177/0013124599032001002

Kawakami, A. (2004). Issues central to the inclusion of Hawaiian culture in K-12 education. Hūlili: Multidisciplinary Research on Native Hawaiian Well-Being,1(1), 111-130.

Keehne, C., Sarsona, M., Kawakami, A., \& Au, K. (2018). Culturally responsive instruction and literacy learning. Journal of Literacy Research, 50(2), 141-166. https://doi.org/10.1177/1086296X18767226

Lopez, S., \& Louis, M. (2009). The principles of strengths-based education. Journal of College and Character, 10, 1-7. https://doi.org/10.2202/1940-1639.1041

McCarty, T., \& Lee, T. (2014). Critical culturally sustaining/revitalizing pedagogy and indigenous education sovereignty. Harvard Educational Review, 84(1), 101-124. https://doi.org/10.17763/haer.84.1.q83746nl5pj34216

McVittie, J., Webber, G., Miller, D., \& Hellsten, L. (2020). Pathways, philosophies, and pedagogies: Conversations with teacher educators about place-based education. 
Canadian Journal of Environmental Education, 23(1), 33-49.

https://cjee.lakeheadu.ca/article/view/1636/951

Meyer, M., (2010, October 21). An introduction to indigenous epistimology [video]. https://www.youtube.com/watch?reload $=9 \& v=\mid m J J i 1 i B d z c$

Moll, L., Amanti, C., Neff, D., \& Gonzalez, N. (1992). Funds of knowledge for teaching: Using a qualitative approach to connect homes and classroom. Theory into Practice, 31(2), 132-141. http://dx.doi.org/10.1080/00405849209543534

Office of Hawaiian Affairs Research Division. (2017). A native Hawaiian focus on the Hawai' $i$ public school system, SY2015. Ho'ona'auao (Education) Fact Sheet, 2017 (1).

Ohnuma, K. (2008). "Aloha Spirit" and the cultural politics of sentiment as national belonging. The Contemporary Pacific, 20(2), 365-394. 10.1353/cp.0.0005

Paris, D. (2012). Culturally sustaining pedagogy: A needed change in stance, terminology, and practice. Educational Researcher, 41(3), 93-97. https://doi.org/10.3102/0013189X12441244

Paris, D., \& Alim, H. S. (2017). Culturally sustaining pedagogies: Teaching and learning for justice in a changing world. Teacher's College Press.

Poepoe, J.K. (1909). Aloha au o Mahiki. In Higashi-Kanahele, K. (Ed.). Pele Keahialoa (pp. 121). Edith Kanakaole Foundation (2014).

Pollock, M., Deckman, S., Mira, M., \& Shalaby, C. (2010). "What can I do?” Three necessary tensions in teaching teachers about race. Journal of Teacher Education, 61(3), 211 224. http://dx.doi.org/10.1177/0022487109354089

Pukui, M. K., Elbert, S. H., \& Mookini, E. T. (1998). Place Names of Hawaii. University of Hawaii Press.

Pukui, M. K., \& Elbert, S. H. (1986). Hawaiian dictionary. University of Hawaii Press.

Pukui, M. K. (1983). Olelo Noeau: Hawaiian proverbs and poetical sayings, Bishop Museum Press.

Tharp, R., \& Gallimore, R. (1988). Rousing minds to life: Teaching, learning, and schooling in social context. Cambridge University Press.

Tharp, R., Jordan, C., Speidel, G., Au, K., Klein, T., Calkins, R., Sloat, K., \& Gallimore, R. (2007). Education and Native Hawaiian children: Revisiting KEEP.

Tibbets, K., Kahakalau, K., \& Johnson, Z. (2007). Education with Aloha and student assets. Hülili: Multidisciplinary Research on Native Hawaiian Well-Being, 4, 147-181.

Schonleber, N. (2007). Culturally congruent teaching strategies: Voices from the field. Hülili: Multidisciplinary Research on Native Hawaiian Well-Being, 4(1), 239-264.

Semken, S., Ward, E., Moosavi, S., \& Chinn, P. (2017). Place-based education in geoscience: Theory, research, practice and assessment. Journal of Geoscience Education, 65, 542562.

Smith, G. (2002). Place Based Education: Learning to Be Where We Are, The Phi Delta Kappan, 83(8), 584-594. https://doi.org/10.1177/003172170208300806 